\title{
Observational Studies Requested by European Health Authorities: Governmental Interference or an Enhancement of Everyday Urological Practice? The Hexvix ${ }^{\circledR}$ Observational Patients Evaluation Study as an Example of What to Expect
}

\author{
Didier Jacqmin ${ }^{d}$ Patrice Jichlinski ${ }^{a}$ Laurent Molinier ${ }^{b} \quad$ Alexandre de la Taille \\ Jacques Irani ${ }^{f}$ Bernard Malavaud $^{c}$ \\ ${ }^{a}$ Department of Urology, Centre Hospitalier Universitaire Vaudois, Lausanne, Switzerland; ${ }^{b}$ Department of Medical \\ Information, Hôtel-Dieu Saint-Jacques, and ' Department of Urology, Institut Universitaire du Cancer, Toulouse, \\ d Department of Urology, Hôpital Civil, Strasbourg, e Department of Urology, Hôpital Henri Mondor, Créteil, and

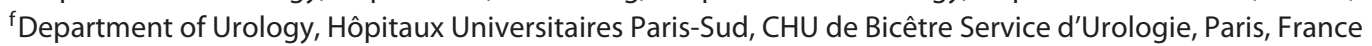

\section{Keywords}

European Union regulation - Observational studies .

Hexaminolevulinate $\cdot$ Non-muscle invasive bladder cancer

\begin{abstract}
Objective: The Hexvix ${ }^{\circledR}$ Observational Patients Evaluation (HOPE) study was designed to determine the extent of distribution of the use of hexaminolevulinate in the diagnosis of non-muscle invasive bladder cancer (NMIBC) and assess patient and treatment characteristics associated with different endoscopic modalities and to address the French authorities' request for information on routine practices for NMIBC diagnosis and surveillance. Patients and Methods: A prospective, observational study in 30 centres in France with fluorescence endoscopy equipment available. All candidates for endoscopy with transurethral resection who gave their consent were eligible. The primary endpoint was the proportion of patients with an NMIBC diagnosis performed with hexaminolevulinate. Results: 506 patients were includ-
\end{abstract}

\section{KARGER}

(C) 2017 S. Karger AG, Basel

E-Mail karger@karger.com

www.karger.com/uin ed: 252 (49.8\%) diagnosed with hexaminolevulinate and 254 (50.2\%) with white-light endoscopy alone. There were more patients with tumour recurrence, multiple lesions, lesions with a diameter $<3 \mathrm{~cm}$, stage Ta disease, and grade 1 lesions in the hexaminolevulinate group. The first quartile median recurrence-free survival time was 310 days in the hexaminolevulinate group and 144 days in the standard-endoscopy group ( $p=0.0015$ ). Conclusion: Hexaminolevulinate was in frequent use in France with specific patient and disease characteristics associated with its use. HOPE illustrates the type of data that can be gained in post-authorisation studies to address requests from European health authorities.

(C) 2017 S. Karger AG, Basel

\section{Introduction}

In the European Union (EU) in 2012, 118,280 new cases of urothelial bladder cancer were diagnosed [1]. Non-muscle invasive bladder cancer (NMIBC) accounts

Professor Didier Jacqmin

Département d'Urologie

Hôpital Civil

1 place de l'Hôpital, BP 426, FR-67091 Strasbourg Cedex (France)

E-Mail ghdj@free.fr 
for approximately $75 \%$ of newly diagnosed bladder cancers, and $60-70 \%$ of NMIBC patients are expected to experience a relapse of the cancers [2]. Outcomes of NMIBC can be optimised with precise risk-stratification of recurrence and progression, adapted adjuvant intravesical treatments and follow-up, but the duration and intensity of follow-up in NMIBC entail high cost-ratios per patient $[3,4]$. Endoscopy is the mainstay of diagnosis and surveillance of NMIBC. Compared with standard whitelight endoscopy, photodynamic diagnosis (PDD) with blue light and the photosensitiser hexaminolevulinate (Hexvix ${ }^{\circledR}$; Ipsen, Paris, France) improves the visualisation of bladder tumours, reduces residual tumour rates by at least $20 \%$ and improves recurrence-free survival [5-14].

Following the registration of hexaminolevulinate in France, the French authorities asked for more information on routine practices for diagnosis and surveillance of NMIBC. Consequently, the Hexvix ${ }^{\circledR}$ Observational Patients Evaluation (HOPE) study was conducted to determine the distribution of hexaminolevulinate use in the diagnosis of NMIBC, and assess the patient and treatment characteristics associated with different endoscopic modalities (white- or blue-light). This request predated but anticipated the recent change in EU regulations that strongly promote post-authorisation studies across Europe $[15,16]$.

The HOPE study addresses many of the specific requests listed in the EU regulations (such as the need to generate unbiased efficacy data in the general population and to gather robust information of the use of medicinal products in different sub-populations), and may therefore be a good example of the relevance for clinicians and Health Authorities alike of properly designed observational studies.

\section{Patients and Methods}

The study was declared to the appropriate French authorities and all patients received all relevant information and gave consent before inclusion in the study.

\section{Investigator Sites and Patient Selection}

In September 2009, the French Health Authority-approved Scientific Committee (D.J., B.M., L.M., A.T., P.J., J.I.) contacted all 50 centres in France that had fluorescence endoscopy equipment available at that time. The centres had to have a minimal experience of 3 months in the use of blue-light endoscopy. The members of the Scientific Committee were excluded from the list of investigators in order to maintain the independent nature of the study.

Fifteen of the contacted centres declined to participate. The target was to include 30 centres in the study. Fifteen centres were initially included, and this was increased progressively until a maximum of 30 active centres was achieved. The centres were stratified according to the type of healthcare institution, the number of transurethral resections (TUR), and the type of endoscopic equipment to give a good representation of the national spread of centres.

All consenting patients who were candidates for an endoscopy with TUR were eligible. Each centre included the first 20 consecutive patients meeting these criteria. The choice of the technique (standard white-light or blue-light fluorescence endoscopy) was at the discretion of each investigator. Patients were enrolled between November 2009 and November 2011 with the last patient visit in January 2013.

\section{Study Design}

The HOPE study was a prospective, observational and noninterventional study. Following inclusion, data collection was ongoing according to the routine practices in each centre. No additional assessments, treatments or other investigations were requested.

The follow-up period was 12 months. Given the duration of the follow-up period, there was a high chance of losing patients to follow-up or of physicians changing jobs. Therefore, regular reminders (e-mail and/or phone call) to participating physicians were scheduled. The results were represented according to the duration of follow-up, that is, less or more than 300 days.

\section{Information Collected}

Information was gathered on the type of the participating centre, number of beds, number of beds in the urology department, number of urologists, number of transurethral resection of the bladder (TURB), and equipment available.

At the inclusion visit, patient characteristics (age, gender, Charlson Comorbidity Index), history of disease (first diagnosis or recurrence), exposure to risk factors for bladder cancer, information on TURB and other treatment, and other information on ambulatory care and hospitalisation were all collected. Following the European Association of Urology (EAU) guidelines on NMIBC, the items of the EORTC bladder calculator [17] (presence of carcinoma in situ, number and size of lesions, T stage, grade, recurrence) were collected whenever applicable. At subsequent visits, information was collected as per standard practice at each centre.

\section{Statistics and Sample Size Calculation}

The primary endpoint was the proportion of patients with NMIBC who had diagnosis performed with hexaminolevulinate (with 95\% confidence intervals [CIs]). The secondary endpoints were comparison between the 2 populations (diagnosis with or without hexaminolevulinate) of patient characteristics, disease characteristics, care management (ambulatory vs. hospitalised care), surgery or medical management during follow-up, frequency of visits, date of first recurrence, occurrence of adverse events, and investigator site characteristics.

Comparisons between the 2 populations used the Student test or Wilcoxon test, or chi-square Fisher's exact test for categorical variables. An exploratory analysis was conducted on the time to recurrence and time to progression in the 2 populations using Kaplan-Meier techniques.

The calculation of the sample size was based on the hypothesis that $20 \%$ of the patients would be diagnosed using hexaminolevu-
A Future Standard Requirement of

European Health Authorities? HOPE Study
Urol Int 2017;99:358-366

DOI: $10.1159 / 000477973$ 
linate and that $15 \%$ of the patients would be lost to follow-up. It was estimated that 600 patients would be needed to obtain a CI of $95 \%$ with a precision of $3.5 \%$. The estimation that $20 \%$ of patients would be diagnosed using hexaminolevulinate was based upon the Association Française d'Urologie guidelines, which state that the preferential indications of hexaminolevulinate are suspected of high-grade bladder lesions (isolated high-grade cytology without cystoscopic visible lesions) and previous history of high-risk tumours (T1-G3 and/or carcinoma in situ) [2].

\section{Results}

\section{Characteristics of Investigator Sites}

Fifteen of the 50 centres declined participation, and the data sources could not be verified for 5 centres. Among the 30 centres that were included, $56.7 \%$ belong to the public health service (12 university hospitals and 5 general hospitals) and $43.3 \%$ to the private health service (11 private hospitals and 2 comprehensive cancer centres). The median (range) number of beds dedicated to urology was 26 (14-54), with a median of 4 (2-8) permanent urologists.

\section{Comparison between Patient Groups}

From November 2009 to December 2011, 561 patients were included; 287 (51.2\%) were diagnosed with hexaminolevulinate and 274 (48.8\%) with white-light (standard) endoscopy alone. In 4 centres, full data monitoring was not possible, and patients from these centres $(n=55)$ were excluded from the analysis. Therefore, 506 patients were retained for assessment: $252(49.8 \%)$ were diagnosed with hexaminolevulinate and 254 (50.2\%) with standard endoscopy. Of these patients, $408(80.6 \%)$ were diagnosed with NMIBC (192 and 216 in the hexaminolevulinate and standard-endoscopy groups, respectively).

The 2 groups were well balanced for gender, occupational hazard and smoking status (Table 1), but in the group that was diagnosed with the use of hexaminolevulinate, patients were significantly younger and had a better performance status. Significant differences were observed between the 2 groups on the basis of bladder calculator items [17]. In the group that was diagnosed with the use of hexaminolevulinate, there were more multiple lesions, more lesions with a diameter $<3 \mathrm{~cm}$, more patients with tumour recurrence, more stage Ta disease and more grade 1 lesions (Table 1). The presence of odds ratio (OR) was similar in both groups.

Before TURB, most patients (69.4\%) underwent at least one additional examination with uroculture (45.3\%), fibroscopy (52.9\%) and cytology (26.7\%). Imaging (35.9 and $24.5 \%$ had an abdominal ultrasound or computed tomography [CT] scan, respectively) was conducted significantly more frequently in the standard endoscopy group than in the hexaminolevulinate group (abdominal ultrasound: 47.4 and $24.0 \%, p<0.001$; and CT scan: 31.3 and $17.5 \%, p=0.001$, respectively).

Nearly all the patients (99.4\%) were hospitalised for TURB with a median duration of 5 days in the standard endoscopy group and 4 days in the hexaminolevulinate group $(p=0.014)$. Cystoscopy was followed by resection of $1-3$ lesions in $61.6 \%$ of TUR and of $\geq 4$ lesions in $37.2 \%$ of TUR. Prophylactic antibiotics were prescribed in 50.3\% of patients, with $12.3 \%$ receiving an early postoperative instillation of mitomycin C (Ametycin).

At baseline, 269 out of 506 (53.2\%) patients had a suspected recurrence of bladder cancer (Table 2). The number of previous TURB and time from previous TURB to present recurrence were similar between groups.

\section{Follow-up Exploratory Analysis}

The median (95\% CI) follow-up of the 408 patients diagnosed with NMIBC was $276(238-290)$ days in the hexaminolevulinate group and $184(148-212)$ days in the standard endoscopy group ( $p=0.0013)$. Of the $408 \mathrm{pa}-$ tients, $361(88.5 \%)$ had at least one urological follow-up visit (median = 2 visits; range $1-6)$ and $182(50.4 \%)$ had intravesical instillations at follow-up (95/173 [54.9\%] in the hexaminolevulinate group and $87 / 188$ [46.3\%] in the standard endoscopy group; $p=0.10$ ).

The median recurrence-free survival time was not reached during the follow-up of this study. The first quartile median $(95 \% \mathrm{CI})$ recurrence-free survival was 310 (244-377) days in the hexaminolevulinate group and 144 (113-191) days in the standard endoscopy group (Fig. 1, $p=0.0015$, log-rank test). The 1-year, recurrence-free survival rate $(95 \% \mathrm{CI})$ was $54 \%(42-67 \%)$ in the hexaminolevulinate group and $40 \%(25-53 \%)$ in the standard endoscopy group. The use of hexaminolevulinate was not associated with a decrease in the relative risk of muscle-invasive progression (odds ratio [OR] 0.29 ; $95 \%$ CI $0.05-1.54 ; p=0.146$ ). The risk of recurrence at 1 year was lower in the hexaminolevulinate group than the predicted recurrence rates using the EORTC bladder calculator [17], whereas the observed recurrence rates in the standard endoscopy group were very similar to the predicted rates. The number of patients in the HOPE study with a low risk of recurrence ( $15 \%$ at 1 year) or high risk of recurrence ( $61 \%$ at 1 year) according to the bladder calculator was too low to make a comparison, but among those with an intermediate
360

Urol Int 2017;99:358-366 DOI: $10.1159 / 000477973$
Jacqmin/Jichlinski/Molinier/de la Taille/ Irani/Malavaud 
Table 1. Characteristics of the 506 assessable patients in HOPE

\begin{tabular}{|c|c|c|c|c|}
\hline \multirow[t]{2}{*}{ Characteristics } & \multirow[t]{2}{*}{ Total $(n=506)$} & \multicolumn{2}{|c|}{ Hexaminolevulinate } & \multirow[t]{2}{*}{$p$ value } \\
\hline & & yes $(n=252)$ & no $(n=254)$ & \\
\hline \multicolumn{5}{|l|}{ Patient characteristics } \\
\hline Gender, $n(\%)$ & & & & 0.374 \\
\hline Male & $416(82.2)$ & $211(83.7)$ & $205(80.7)$ & \\
\hline Female & $90(17.8)$ & $41(16.3)$ & $49(19.3)$ & \\
\hline Age, years & & & & 0.018 \\
\hline Median (range) & $71(24-98)$ & $70(42-92)$ & $72(24-98)$ & \\
\hline ECOG-PS & & & & 0.002 \\
\hline $0-1$ & $409(88.3)$ & $221(92.9)$ & $188(83.6)$ & \\
\hline$\geq 2$ & $54(11.7)$ & $17(7.1)$ & $37(16.4)$ & \\
\hline Not documented & 43 & 14 & 29 & \\
\hline Occupational hazard, $n(\%)$ & & & & 0.131 \\
\hline Yes & $18(3.9)$ & $6(2.6)$ & $12(5.3)$ & \\
\hline No & $442(87.4)$ & $227(90.1)$ & $215(84.6)$ & \\
\hline Not documented & 46 & 19 & 27 & \\
\hline Smoking status, $n(\%)$ & & & & 0.82 \\
\hline Smoker & $114(23.6)$ & $59(24.3)$ & $55(22.8)$ & \\
\hline Previous smoker & $226(46.7)$ & $110(45.3)$ & $116(48.1)$ & \\
\hline Never smoking & $144(29.8)$ & $74(30.5)$ & $70(29.1)$ & \\
\hline Not documented & 22 & 9 & 13 & \\
\hline \multicolumn{5}{|l|}{ Disease characteristics } \\
\hline \multicolumn{5}{|l|}{ Bladder calculator items [17] } \\
\hline Number of lesions, $n(\%)$ & & & & $<0.001$ \\
\hline 1 & $152(35.3)$ & $51(25.2)$ & $101(44.1)$ & \\
\hline $2-7$ & $252(58.5)$ & $133(65.8)$ & $119(52.0)$ & \\
\hline$\geq 8$ & $27(6.3)$ & $18(8.9)$ & $9(3.9)$ & \\
\hline Not documented & 75 & 50 & 25 & \\
\hline Diameter of the main lesion, $n(\%)$ & & & & 0.002 \\
\hline$<3 \mathrm{~cm}$ & $297(72.6)$ & $154(79.8)$ & $143(66.2)$ & \\
\hline$\geq 3 \mathrm{~cm}$ & $112(27.4)$ & $39(20.2)$ & $73(33.8)$ & \\
\hline Not documented & 97 & 59 & 38 & \\
\hline Recurrence rate, $n(\%)$ & & & & $<0.001$ \\
\hline Primary & $229(53.0)$ & $81(40.1)$ & $148(64.3)$ & \\
\hline Recurrence $\leq 1 /$ year & $119(27.5)$ & $74(36.6)$ & $45(19.6)$ & \\
\hline Recurrence $>1 /$ year & $84(19.4)$ & $47(23.3)$ & $37(16.1)$ & \\
\hline Not documented & 74 & 50 & 24 & \\
\hline Stage, $n(\%)$ & & & & 0.002 \\
\hline $\mathrm{Ta}$ & 267 (69.9) & $140(77.3)$ & $127(63.2)$ & \\
\hline $\mathrm{T} 1$ & $115(30.1)$ & $41(22.7)$ & $74(36.8)$ & \\
\hline Not documented & 124 & 71 & 53 & \\
\hline Grade, $n(\%)$ & & & & $<0.001$ \\
\hline 1 & $112(26.9)$ & $67(35.3)$ & $45(19.9)$ & \\
\hline 2 & $147(35.3)$ & $70(36.8)$ & $77(34.1)$ & \\
\hline 3 & $157(37.7)$ & $53(27.9)$ & $104(46.0)$ & \\
\hline Not documented & 90 & 62 & 28 & \\
\hline CIS, $n(\%)$ & & & & 0.67 \\
\hline Yes & $69(15.8)$ & $34(16.6)$ & $35(15.1)$ & \\
\hline Not documented & 69 & 47 & 22 & \\
\hline
\end{tabular}

ECOG, Eastern Cooperative Oncology Group; PS, performance status; CIS, carcinoma in situ.

A Future Standard Requirement of European Health Authorities? HOPE Study
Urol Int 2017;99:358-366 DOI: $10.1159 / 000477973$ 
Table 2. Disease history of relapsing patients

\begin{tabular}{|c|c|c|c|c|}
\hline \multirow[t]{2}{*}{ Variables } & \multirow[t]{2}{*}{ Total $(n=269)$} & \multicolumn{2}{|c|}{ Hexaminolevulinate } & \multirow[t]{2}{*}{$p$ value } \\
\hline & & yes $(n=166)$ & no $(n=103)$ & \\
\hline Previous TUR, $n$ & & & & 0.50 \\
\hline Median (range) & $2(0-18)$ & $2(0-18)$ & $2(1-10)$ & \\
\hline Time from baseline endoscopy and last TUR, months & & & & 0.73 \\
\hline Median (range) & $13(1-307)$ & $13(1-254)$ & $13(2-307)$ & \\
\hline Stage at the previous TUR, $n(\%)$ & & & & 0.02 \\
\hline $\mathrm{Ta}$ & $131(65.2)$ & $90(72.6)$ & $41(53.2)$ & \\
\hline $\mathrm{T} 1$ & $67(33.3)$ & $33(26.6)$ & $34(44.2)$ & \\
\hline $\mathrm{T} 2$ & $3(1.5)$ & $1(0.8)$ & $2(2.6)$ & \\
\hline Unknown/NA & 68 & 42 & 20 & \\
\hline Grade at the previous TUR, $n(\%)$ & & & & 0.09 \\
\hline Grade 1 & $47(22.3)$ & $32(24.8)$ & $15(18.3)$ & \\
\hline Grade 2 & $83(39.3)$ & $55(42.6)$ & $28(34.1)$ & \\
\hline Grade 3 & $81(38.4)$ & $42(32.6)$ & $39(47.6)$ & \\
\hline Unknown/NA & 58 & 37 & 21 & \\
\hline CIS, $n(\%)$ & & & & 0.47 \\
\hline Yes & $41(18.1)$ & $23(16.7)$ & $18(20.5)$ & \\
\hline Unknown/NA & 43 & 28 & 15 & \\
\hline Previous instillations, $n(\%)$ & & & & 0.46 \\
\hline Yes & $138(53.5)$ & $89(55.3)$ & $49(50.5)$ & \\
\hline Unknown/NA & 11 & 5 & 6 & \\
\hline If previous instillations, $n(\%)$ & & & & 0.07 \\
\hline Mitomycin & $37(26.8)$ & $29(32.6)$ & $8(16.3)$ & \\
\hline $\mathrm{BCG}$ & $96(69.6)$ & $58(65.2)$ & $38(77.6)$ & \\
\hline Mitomycin plus BCG & $5(3.6)$ & $2(2.2)$ & $3(6.1)$ & \\
\hline
\end{tabular}

TUR, transurethral resection; NA, not applicable; CIS, carcinoma in situ; BCG, Bacillus Calmette-Guérin.

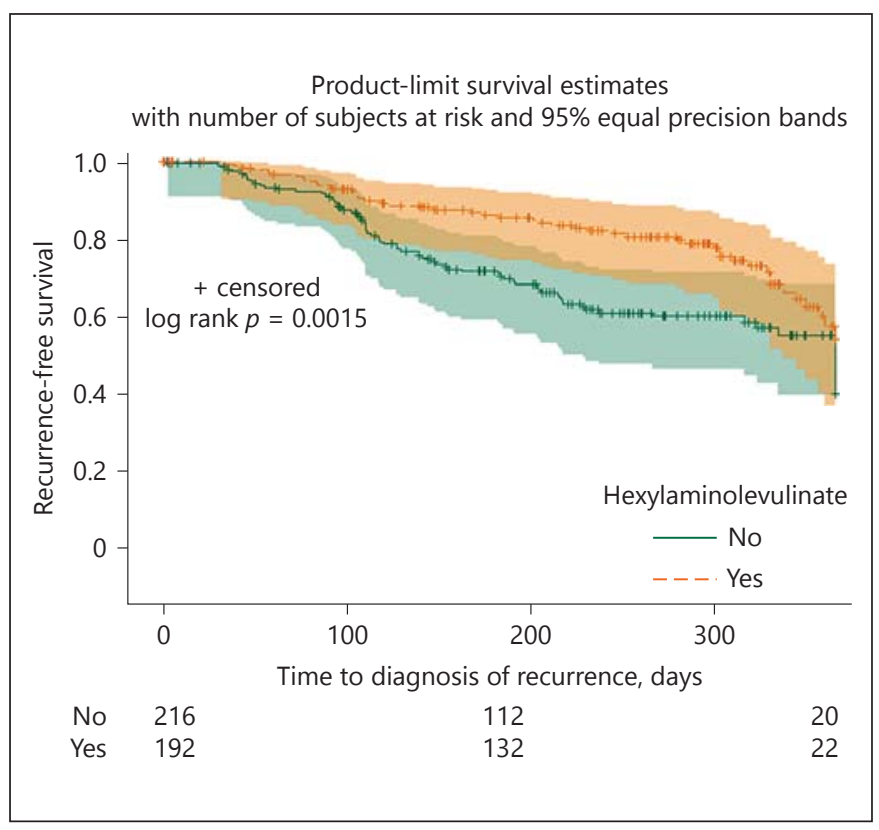

Fig. 1. Recurrence-free survival based on the use of hexaminolevulinate. risk, the rate of recurrence at 1 year was lower in the hexaminolevulinate group than the standard endoscopy group (OR 0.45; 95\% CI 0.22-0.89).

\section{Adverse Events}

During the study, 317 patients were exposed to hexaminolevulinate. One patient was hospitalised because of a general status impairment not related to the use of hexaminolevulinate. Twenty deaths were reported: 17 were related to the disease progression, one to a prostate cancer, one to a cardiac failure, and one to severe domestic burns. No death was related to the use of hexaminolevulinate.

\section{Discussion}

The recent announcement from the EU [15] will result in a greater frequency of observational studies like the HOPE study in the future. This change in policy reflects calls for more information on the real-world pattern of care and use of medicinal products [18], which is particu-
362
Urol Int 2017;99:358-366 DOI: $10.1159 / 000477973$
Jacqmin/Jichlinski/Molinier/de la Taille/ Irani/Malavaud 
larly relevant for NMIBC, a prevalent cancer whose management is costly for the community and intrusive for the patient. Indeed, well-designed observational studies may help determine whether the efficacy and tolerability results of randomised clinical trials are reproducible in the more diverse settings and patterns of care in everyday use. The HOPE study was conducted in response to a request from the French Health Authority for more information on routine practices for diagnosis and surveillance of NMIBC.

With regard to efficacy, the increased detection and the decreased recurrence observed in the HOPE study with PDD were consistent with the pivotal trials by Fradet et al. [5] and Grossman et al. [11], and the meta-analysis by Burger et al. [14]. The HOPE study, therefore, provides evidence that PDD use in everyday clinical routine replicates the positive results obtained in the research setting. An improvement in the detection of NMIBC with bluelight cystoscopy with hexaminolevulinate as an adjunct to white-light cystoscopy (versus this technique alone) has also been shown in routine clinical practice in, for example, Spain [19] and Germany [20].

Information about patterns of everyday use makes post-authorisation observational studies crucial for Health Authorities to properly assess and optimise costeffective cancer care [21]. This is a particular strength of the HOPE study, which provides unexpected but revealing information on the frequency of hexaminolevulinate use in French centres, and on the type of patient selected for diagnosis with hexaminolevulinate. There was more frequent use of hexaminolevulinate in the HOPE study than expected ( $49.8 \%$ compared with the predicted $20 \%$ ). The estimated frequency was based upon the previous Association Française d'Urologie guidelines indicating the use of hexaminolevulinate when a high-risk lesion was suspected [2], but the European registration of the product provides a broader indication ("in patients with known or high suspicion of bladder cancer"). The more frequent use of hexaminolevulinate in the HOPE study may reflect the recent update of the French guidelines, which recommend the use of hexaminolevulinate for diagnosis at every TURB [22]. This situation may explain why the frequency of use was difficult to predict. Likewise, the impact of instrument capacity or availability on non-use of hexaminolevulinate cannot be estimated from these data. Many patients had previous TURB and this may also have driven the frequency of hexaminolevulinate use; whether more recent data on the use of diffusion-weighted magnetic resonance imaging in the diagnosis of residual cancer before re-TURB [23] will influ-

A Future Standard Requirement of European Health Authorities? HOPE Study ence the use of blue-light cystoscopy is difficult to predict. However, these findings from the HOPE study do illustrate how important such post-authorisation studies may be to Health Authorities for making accurate cost-effectiveness analyses (but it should be stressed that no costeffectiveness analysis was included in the HOPE study). In this example, the greater-than-expected use of hexaminolevulinate may actually have cost-benefits via more accurate guidance for optimising subsequent treatments that can improve outcome [24]. Improved recurrencefree survival with hexaminolevulinate may be associated with an increase in quality-adjusted life years and improved long-term cost effectiveness [25-27].

Another observation on the patterns of use from HOPE was that hexaminolevulinate was used less often in first episodes and isolated lesions, and more often in multiple lesions and in tumours $<3 \mathrm{~cm}$ and of low stage/grade. There was no particular indication in the EAU guidelines that existed at the time of this trial's commencement that these patient groups should be targeted for diagnosis using hexaminolevulinate [28]. On the other hand, strong recommendations such as urine analysis and urine cytology for the primary assessment of TaT1 bladder tumours [28] were not followed in most patients in the HOPE study. This raises a complex but important question; are there real-life issues that drive more pragmatic practices by the majority of centres and what is the impact of these issues?

The uncertain transition between the research setting and everyday practice spurred the EU to promote postauthorisation efficacy studies, notably when the benefits of the medicinal product may be significantly affected by real-life conditions - which is not the case in the present study - and when the initial efficacy assessment was based on surrogate endpoints. This is appropriate to oncology trials where progression-free survival is widely used as a surrogate as it is often difficult to achieve the appropriate power to detect differences in overall survival, owing to increasing post-progression survival, patient/disease heterogeneity, and variability in the use of active treatments after disease progression [29-31]. Post-authorisation studies, therefore, have the potential to facilitate the introduction of new drugs and new patterns of care (e.g., individualised medicine), opening a promising field of collaboration between the pharmaceutical industry and learned societies such as the EAU, which are in the unique position of federating professionals in Europe across national borders.

One further objective of observational studies is to provide Health Authorities with information on the tol-

Urol Int 2017;99:358-366

DOI: $10.1159 / 000477973$ 
Table 3. Some key strengths and drawbacks of observational studies compared with randomised controlled trials

\begin{tabular}{|c|c|}
\hline & Observational studies \\
\hline \multirow[t]{3}{*}{ Strengths } & $\begin{array}{l}\text { Unbiased assessment of the current management situation vs. RCTs, which have } \\
\text { highly controlled populations and tell us nothing about everyday clinical practice. }\end{array}$ \\
\hline & $\begin{array}{l}\text { Allows comparison of risks and benefits in "real-life" clinical situations vs. RCTs that } \\
\text { have narrow inclusion criteria and standardised treatment regimens that may not } \\
\text { reflect the population that will receive the medicinal product post-authorisation or } \\
\text { the management decisions made in everyday practice. }\end{array}$ \\
\hline & $\begin{array}{l}\text { An idea of what guidelines/labelling is being followed in everyday clinical practice to } \\
\text { feed into cost-effectiveness assessments vs. RCTs, which follow strict guidelines that } \\
\text { may not reflect what happens in different centres. }\end{array}$ \\
\hline \multirow[t]{4}{*}{ Drawbacks } & $\begin{array}{l}\text { Incomplete information vs. RCTs, which allow the gathering of detailed and } \\
\text { complete information at multiple time-points to assess a number of outcomes. }\end{array}$ \\
\hline & $\begin{array}{l}\text { Generally no comparator vs. RCTs that can specify the most appropriate comparator } \\
\text { (placebo or active treatment) and allow a direct assessment between multiple } \\
\text { treatments. }\end{array}$ \\
\hline & $\begin{array}{l}\text { Heterogeneous population - but this can sometimes be a strength vs. RCTs that only } \\
\text { include the specific population of interest, thus reducing confounding factors on } \\
\text { outcomes. }\end{array}$ \\
\hline & $\begin{array}{l}\text { No assessment of confounding factors such as centre-effects vs. RCTs that normally } \\
\text { adjust findings for multiple confounding factors. }\end{array}$ \\
\hline
\end{tabular}

erability of medicinal products when they are used in everyday practice [32-34]. Investigators are encouraged to seek cooperation with Health Authorities, as information from a wide spectrum of patients is needed. HOPE investigators have gathered such information for hexaminolevulinate, thereby confirming the safety profile of this technique in everyday clinical practice.

Other strengths and drawbacks of observational studies are well illustrated by the HOPE study (Table 3 ). However, one drawback of most observational studies is that they focus on patients receiving a particular medicinal product. The HOPE study is unusual in that 2 groups of patients (those having a diagnosis with or without hexaminolevulinate) were compared. Whether such comparative data can be gained from future observational studies will be determined on a case-by-case basis.

\section{Conclusions}

The recent EU regulation to expand the use of postauthorisation studies [15] is aimed at assisting Health $\mathrm{Au}$ thorities in their assessment of the feasibility and costeffectiveness of medicinal products in everyday clinical practice. In future, large-scale and long-term observational studies may be needed to achieve this. The HOPE study was conducted in response to a request from the French Health Authority partly because the management of NMIBC is expensive, because there are no reliable surrogate markers for overall survival, and because endoscopy can have an impact upon outcomes. The increase in detection and the decrease in recurrence observed with PDD in this study were in line with pivotal trials and a meta-analysis.

\section{Acknowledgement}

The authors thank all investigators in the HOPE study: Thomas Albert, Ahmad Atassi, Ibrahim Bah-Clozel, Hervé Baumert, Gérard Benoit, Mohamed Bensmain, André Benzaquin, Philippe Colls, Marc Colombel, Ariane Cortesse, Jean-Luc Descotes, Patrick Dufeuil, Jean-Christophe Fantoni, Jean-Marie Ferriere, Eric Fontaine, Frédéric Girard, Pierre-Charles Henry, Frédéric Jonca, François Kleinclauss, Hervé Letourneux, Patrick Moulu, Christian Pfister, Bertrand Rabut, Vincent Ravery, Olivier Skowron, Xavier Stefaniak, Emmanuel Van Glabeke, and Jochen Walz. The HOPE study was funded by Ipsen. The authors take full responsibility for the content of the paper and thank Martin Gilmour (ESP Bioscience Ltd., Crowthorne, UK) for editorial assistance (supported by Ipsen). 


\section{Disclosure Statement}

The French National Authority for Health (Haute Autorité de Santé) requested that GE Healthcare conduct this study after the registration of Hexvix ${ }^{\circledR}$ on the French market. The authors were selected by GE Healthcare and approved by the French National Authority for Health. All authors received honoraria from GE Healthcare for their work in the design of the tudy, and for the interim and final analyses. The sponsor was responsible for collection of the data. Since the start of the study, ownership changed and Hexvix ${ }^{\circledR}$ is now sold by Ipsen.
D.J. reports of having received personal fees from GE Healthcare and Ipsen during the conduct of the study and personal fees from Ipsen outside the submitted work. P.J. reports on patent BR-9152. F.R. 1998, licensed to Photocure, and of having received royalties from Photocure to EPFL and CHUV University Hospital, Lausanne, Switzerland. L.M. has no conflicts to disclose. A.T. has no conflicts to disclose. J.I. reports of having received personal fees from Ipsen during the conduct of the study; grants, personal fees and non-financial support from Sanofi; grants, personal fees, nonfinancial support and other support from Ipsen outside the submitted work. B.M. reports of having received personal fees from GE Healthcare and Ipsen during the conduct of the study.

\section{References}

1 Ferlay J, Steliarova-Foucher E, Lortet-Tieulent J, Rosso S, Coebergh JW, Comber H, Forman D, Bray F: Cancer incidence and mortality patterns in Europe: estimates for 40 countries in 2012. Eur J Cancer 2013;49: 1374-1403.

2 Pfister C, Roupret M, Neuzillet Y, Larre S, Pignot G, Quintens H, Houede N, Comperat E, Colin P, Roy C, Davin JL, Guy L, Irani J, Lebret T, Coloby P, Soulie M; Les membres du CCAFU: [CCAFU Recommendations 2013: bladder carcinoma]. Prog Urol 2013;23(suppl 2):S105-S125.

3 Botteman MF, Pashos CL, Redaelli A, Laskin B, Hauser R: The health economics of bladder cancer: a comprehensive review of the published literature. Pharmacoeconomics 2003; 21:1315-1330.

4 Sangar VK, Ragavan N, Matanhelia SS, Watson MW, Blades RA: The economic consequences of prostate and bladder cancer in the UK. BJU Int 2005;95:59-63.

5 Fradet Y, Grossman HB, Gomella L, Lerner S, Cookson M, Albala D, Droller MJ: A comparison of hexaminolevulinate fluorescence cystoscopy and white light cystoscopy for the detection of carcinoma in situ in patients with bladder cancer: a phase III, multicenter study. J Urol 2007;178:68-73.

6 Jocham D, Witjes F, Wagner S, Zeylemaker B, van Moorselaar J, Grimm MO, Muschter R, Popken G, Konig F, Knuchel R, Kurth KH: Improved detection and treatment of bladder cancer using hexaminolevulinate imaging: a prospective, phase III multicenter study. J Urol 2005;174:862-866.

7 Jichlinski P, Guillou L, Karlsen SJ, Malmstrom PU, Jocham D, Brennhovd B, Johansson E, Gartner T, Lange N, van den Bergh H, Leisinger HJ: Hexyl aminolevulinate fluorescence cystoscopy: new diagnostic tool for photodiagnosis of superficial bladder cancer - a multicenter study. J Urol 2003;170:226229

8 Karaolides T, Skolarikos A, Bourdoumis A, Konandreas A, Mygdalis V, Thanos A, Deliveliotis C: Hexaminolevulinate-induced fluorescence versus white light during transure- thral resection of noninvasive bladder tumor: does it reduce recurrences? Urology 2012;80: 354-359.

9 Lapini A, Minervini A, Masala A, Schips L, Pycha A, Cindolo L, Giannella R, Martini T, Vittori G, Zani D, Bellomo F, Cosciani Cunico S: A comparison of hexaminolevulinate $\left(\operatorname{Hexvix}\left({ }^{\circledR}\right)\right)$ fluorescence cystoscopy and white-light cystoscopy for detection of bladder cancer: results of the HeRo observational study. Surg Endosc 2012;26:36343641.

10 Geavlete B, Multescu R, Georgescu D, Jecu M, Stanescu F, Geavlete P: Treatment changes and long-term recurrence rates after hexaminolevulinate (HAL) fluorescence cystoscopy: does it really make a difference in patients with non-muscle-invasive bladder cancer (NMIBC)? BJU Int 2012;109:549556.

11 Grossman HB, Stenzl A, Fradet Y, Mynderse LA, Kriegmair M, Witjes JA, Soloway MS, Karl A, Burger M: Long-term decrease in bladder cancer recurrence with hexaminolevulinate enabled fluorescence cystoscopy. J Urol 2012;188:58-62.

12 Hermann GG, Mogensen K, Carlsson S, Marcussen N, Duun S: Fluorescence-guided transurethral resection of bladder tumours reduces bladder tumour recurrence due to less residual tumour tissue in $\mathrm{Ta} / \mathrm{T} 1$ patients: a randomized two-centre study. BJU Int 2011; 108:E297-E303.

13 Yang LP: Hexaminolevulinate blue light cystoscopy: a review of its use in the diagnosis of bladder cancer. Mol Diagn Ther 2014;18:105116.

14 Burger M, Grossman HB, Droller M, Schmidbauer J, Hermann G, Dragoescu O, Ray E, Fradet Y, Karl A, Burgues JP, Witjes JA, Stenzl A, Jichlinski P, Jocham D: Photodynamic diagnosis of non-muscle-invasive bladder cancer with hexaminolevulinate cystoscopy: a meta-analysis of detection and recurrence based on raw data. Eur Urol 2013;64:846854.

15 Commission Delegated Regulation (EU) No $357 / 2014$ of 3 February 2014 supplementing
Directive 2001/83/EC of the European Parliament and of the Council and Regulation (EC) No 726/2004 of the European Parliament and of the Council as regards situations in which post-authorisation efficacy studies may be required Text with EEA relevance. Official Journal of the European Union, 10 April 2014.

16 Stamenkovic S, Solesse A, Zanetti L, Zagury P, Vray M; le groupe Intérêt de santé publique et études post-inscription (ISPEP): [French Health Authority (HAS) Guidance: the postregistration studies on health technologies (drugs, medical devices and instruments): principles and methods]. Therapie 2012;67: 409-421.

17 Sylvester RJ, van der Meijden AP, Oosterlinck W, Witjes JA, Bouffioux C, Denis L, Newling DW, Kurth K: Predicting recurrence and progression in individual patients with stage Ta T1 bladder cancer using EORTC risk tables: a combined analysis of 2596 patients from seven EORTC trials. Eur Urol 2006;49:466-465; discussion 475-467.

18 Bamberger M, Moore N, Lechat P; participants of Round Table $\mathrm{N}^{\circ} 3$ of Giens XXVI: How to improve the clinical development paradigm and its division into phases I, II and III. Therapie 2011;66:331-334, 327330.

19 Palou J, Hernandez C, Solsona E, Abascal R, Burgues J, Rioja C, Cabrera J, Gutierrez C, Rodriguez O, Iborra I, Herranz F, Abascal J, Conde G, Oliva J: Effectiveness of hexaminolevulinate fluorescence cystoscopy for the diagnosis of non-muscle-invasive bladder cancer in daily clinical practice: a Spanish multicentre observational study. BJU Int 2014;116:37-43.

20 Bach T, Bastian PJ, Blana A, Kaminsky A, Keller S, Knoll T, Lang C, Promnitz S, Ubrig B, Keller T, Qvick B, Burger M; OPTIC III Study Group: Optimised photodynamic diagnosis for transurethral resection of the bladder (TURB) in German clinical practice: results of the noninterventional study OPTIC III. World J Urol 2017;35: 737-744
A Future Standard Requirement of European Health Authorities? HOPE Study
Urol Int 2017;99:358-366 DOI: $10.1159 / 000477973$ 
21 Sullivan R, Peppercorn J, Sikora K, Zalcberg J, Meropol NJ, Amir E, Khayat D, Boyle P, Autier P, Tannock IF, Fojo T, Siderov J, Williamson S, Camporesi S, McVie JG, Purushotham AD, Naredi P, Eggermont A, Brennan MF, Steinberg ML, De Ridder M, McCloskey SA, Verellen D, Roberts T, Storme G, Hicks RJ, Ell PJ, Hirsch BR, Carbone DP, Schulman KA, Catchpole P, Taylor D, Geissler J, Brinker NG, Meltzer D, Kerr D, Aapro M: Delivering affordable cancer care in high-income countries. Lancet Oncol 2011;12:933-980.

22 Roupret M, Neuzillet Y, Masson-Lecomte A, Colin P, Comperat E, Dubosq F, Houede N, Larre S, Pignot G, Puech P, Roumiguie M, Xylinas E, Mejean A: [CCAFU french national guidelines 2016-2018 on bladder cancer]. Prog Urol 2016;27(suppl 1):S67-S91.

23 Nakamura Y, Yoshida S, Tanaka H, Inoue M, Ito M, Kijima T, Yokoyama M, Ishioka J, Matsuoka Y, Saito K, Fujii Y, Kihara K: Potential utility of Diffusion-Weighted Magnetic Resonance Imaging in diagnosis of residual bladder cancer before second transurethral resection. Urol Int 2017;98:298-303.

24 Novotny V, Froehner M, Ollig J, Koch R, Zastrow S, Wirth MP: Impact of adjuvant intravesical Bacillus Calmette-Guérin treatment on patients with high-grade T1 bladder cancer. Urol Int 2016;96:136-141.
25 Marteau F, Kornowski A, Bennison C, Tempest MJ, Mariappan P, Witjes JA: Cost-effectiveness of the optical imaging agent hexaminolevulinate for patients undergoing initial transurethral resection of non-muscle invasive bladder cancer tumours. Eur Urol Suppl 2013;12:125.

26 Bennison C, Tempest MJ, Marteau F, et al: How investment in hexaminolevulinate technology would be beneficial to patients and healthcare system in non-muscle invasive bladder cancer in Italy? Paper presented at: 10th Health Technology Assessment International Annual Meeting, 2013, Seoul, Korea.

27 Roupret M, Malavaud B, Molinier L, Leleu H, Blachier M, Marteau F: [Cost-effectiveness of transurethral resection of the bladder with blue light in patients with non muscle invasive bladder cancer in France]. Prog Urol 2015;25: 256-264.

28 Babjuk M, Oosterlinck W, Sylvester R, Kaasinen E, Böhle A, Palou J: Guidelines on TaT1 (Non-Muscle Invasive) Bladder Cancer. Arnhem, Eur Assoc Urol, 2009.

29 Broglio KR, Berry DA: Detecting an overall survival benefit that is derived from progression-free survival. J Natl Cancer Inst 2009; 101:1642-1649.

30 Di Leo A, Bleiberg H, Buyse M: Overall survival is not a realistic end point for clinical trials of new drugs in advanced solid tumors: a critical assessment based on recently reported phase III trials in colorectal and breast cancer. J Clin Oncol 2003;21:2045-2047.

31 Negrier S, Bushmakin AG, Cappelleri JC, Korytowsky B, Sandin R, Charbonneau C, Michaelson MD, Figlin RA, Motzer RJ: Assessment of progression-free survival as a surrogate end-point for overall survival in patients with metastatic renal cell carcinoma. Eur J Cancer 2014;50:1766-1771.

32 Avery AJ, Anderson C, Bond CM, Fortnum H, Gifford A, Hannaford PC, Hazell L, Krska J, Lee AJ, McLernon DJ, Murphy E, Shakir S, Watson MC: Evaluation of patient reporting of adverse drug reactions to the UK "Yellow Card Scheme": literature review, descriptive and qualitative analyses, and questionnaire surveys. Health technology assessment 2011; 15:1-234, iii-iv.

33 Gnadinger M, Mellinghoff HU: The out-offocus bias in drug surveillance. Eur J Clin Pharmacol 2013;69:357-359.

34 O'Neill RT: Biostatistical considerations in pharmacovigilance and pharmacoepidemiology: linking quantitative risk assessment in pre-market licensure application safety data, post-market alert reports and formal epidemiological studies. Stat Med 1998;17:18511858; discussion 1859-1862. 